Check for updates

Cite this: RSC Adv., 2021, 11, 15927

\title{
Oxygen reduction reaction activity of an iron phthalocyanine/graphene oxide nanocomposite $\uparrow$
}

\author{
Kenichiro Irisa, ${ }^{a}$ Kazuto Hatakeyama, (D) *b Soichiro Yoshimoto, (ID ${ }^{\mathrm{b}}$ Michio Koinuma*b \\ and Shintaro Ida (D) *b
}

Electrocatalysts with metal-nitrogen-carbon $(\mathrm{M}-\mathrm{N}-\mathrm{C})$ sites have recently attracted much attention as potential catalysts for the oxygen reduction reaction (ORR), and a hybrid of iron phthalocyanine (FePc) and reduced graphene oxide $(\mathrm{rGO})$ is one of the promising candidates. Herein, a FePc/GO nanocomposite was synthesized by electrostatic deposition on the electrode. The electrochemically reduced $\mathrm{FePc} / \mathrm{GO}$ nanocomposite $\left(\mathrm{ER}(\mathrm{FePc} / \mathrm{GO})\right.$ ) contained $\mathrm{Fe}^{2+}$ centers in well reduced graphene sites without agglomeration. The ER(FePc/GO) exhibited high ORR activity with an ORR onset ( $\left.E_{\text {onset }}\right)$ and half-wave potential $\left(E_{1 / 2}\right)$ of 0.97 and $0.86 \mathrm{~V}$, respectively. Furthermore, the ORR activity successfully improved by adding an electrolyte such as $\mathrm{KCl}$ or $\mathrm{KNO}_{3}$. The small $\mathrm{H}_{2} \mathrm{O}_{2}$ yield of $2 \%$, superior tolerance to methanol addition and high-durability indicate that the $\mathrm{ER}(\mathrm{FePc} / \mathrm{GO})$ is a promising electrocatalyst. Theoretical studies, indicating that the presence of $\mathrm{Cl}^{-}$and $\mathrm{NO}_{3}{ }^{-}$ions lowered the conversion energy barrier, strongly supported the experimental results.

Received 6th February 2021 Accepted 23rd April 2021

DOI: 10.1039/d1ra01001h

rsc.li/rsc-advances
However, ideal hybrids between monolayer GO nanosheets and FePc have not yet been achieved because previously reported FePc/GO nanocomposites were prepared using a poorlydispersed $\mathrm{FePc}$ in ethanol $(\mathrm{EtOH})$ or $\mathrm{N}, \mathrm{N}$-dimethylformamide (DMF) containing a large amount of aggregated FePc. ${ }^{22,23}$ An ideal monolayer FePc/GO hybrid is expected to exhibit greater catalytic activity than previously reported FePc/rGO composites.

In the present study, we report a composite that exhibits better ORR activity than any previously reported FePc/rGO nanocomposite. The new composite was prepared by electrostatic interaction between GO nanosheet and FePc on the electrode. Furthermore, we demonstrate from both experimental and theoretical viewpoints that the addition of electronwithdrawing ions to the electrolyte solution positively affects the ORR activity of the nanocomposite.

\section{Experimental}

\section{Materials}

All chemicals were obtained from commercial suppliers and were used without further purification. Iron phthalocyanine (FePc, 90\%, Sigma-Aldrich), chloroform (99.0\%, Wako), graphite powder (98.0\%, Wako), and DMF (99.0\%, Wako) were used.

\section{Synthesis of GO}

GO was prepared using a modified Hummers' method..,27 Graphite powder $(2 \mathrm{~g}), \mathrm{NaNO}_{3}(2 \mathrm{~g})$ and $\mathrm{H}_{2} \mathrm{SO}_{4}(92 \mathrm{~mL})$ was mixed at $0{ }^{\circ} \mathrm{C}$ and $\mathrm{KMnO}_{4}(10 \mathrm{~g})$ was added to the mixture slowly. The resulting mixture was diluted with deionized water (DI), then $30 \% \mathrm{H}_{2} \mathrm{O}_{2}(5 \mathrm{~mL})$ was added, centrifuged, washed 
with $5 \% \mathrm{HCl}$ solution and DI water, and dried in an oven at $50{ }^{\circ} \mathrm{C}$ for 2 days. The resultant graphite oxide was exfoliated in DI water by ultrasonication (KUBOTA 3700) for $2 \mathrm{~h}$; the sonicated solution was subsequently centrifuged at $8000 \mathrm{rpm}$ to separate the GO from graphite oxide. The obtained GO/water dispersion was dried at $50{ }^{\circ} \mathrm{C}$ to obtain GO powder.

\section{Preparation of electrocatalyst}

A GO/DMF dispersion $\left(0.5 \mathrm{~g} \mathrm{~L}^{-1}\right)$ was prepared by sonicating the prepared GO powder in DMF for $2 \mathrm{~h}$. An $\mathrm{FePc} / \mathrm{CHCl}_{3}$ dispersion $\left(0.5 \mathrm{~g} \mathrm{~L}^{-1}\right)$ was prepared by sonicating $\mathrm{FePc}$ in $\mathrm{CHCl}_{3}$ for $1 \mathrm{~h}$. $\mathrm{FePc} /$ GO was prepared by mixing $20 \mu \mathrm{L}$ of the GO/DMF dispersion $(0.5 \mathrm{~g}$ $\left.\mathrm{L}^{-1}\right)$ and $20 \mu \mathrm{L}$ of the $\mathrm{FePc} / \mathrm{CHCl}_{3}$ dispersion $\left(0.5 \mathrm{~g} \mathrm{~L}^{-1}\right)$ on a glassy carbon (GC) electrode. Furthermore, the FePc/GO was reduced electrochemically to $\mathrm{ER}(\mathrm{FePc} / \mathrm{GO})$ by applying a potential of $-1.3 \mathrm{~V}$ (vs. $\mathrm{Ag} / \mathrm{AgCl}, \mathrm{pH} 13$ ) for $10 \mathrm{~min}$ to the GC electrode coated with FePc/GO in $\mathrm{N}_{2}$-saturated 0.1 $\mathrm{M} \mathrm{KOH}$.

\section{Materials characterization}

The height and width of the resultant GO nanosheets were investigated by atomic force microscopy (AFM; Nanocute, Hitachi High-Tech Sci. Co.). X-ray diffraction (XRD) patterns were collected on a Rigaku SmartLab $3 \mathrm{~kW}$ X-ray diffractometer equipped with a $\mathrm{Cu} \mathrm{K} \alpha(\lambda=0.154 \mathrm{~nm})$ radiation source. A fieldemission Scanning electron microscopy (FE-SEM) images were recorded on a SU-8000 (Hitachi High-Technologies Corporation) microscope. Elemental analyses and chemical-state profiles were conducted using an X-ray photoelectron spectroscopy (XPS) apparatus (ThetaProbe, Thermo Fisher Scientific). The $\mathrm{C}$ 1s XPS spectra were fitted based on of the contributions of eight groups $(-\mathrm{COOH}, \mathrm{C}=\mathrm{O}, \mathrm{C}-\mathrm{O}-\mathrm{C}, \mathrm{C}-\mathrm{OH}$, $\mathrm{sp}^{3} \mathrm{C}-\mathrm{C}, \mathrm{C}-\mathrm{H}$ defects, $\mathrm{C}-\mathrm{N}$, and $\mathrm{sp}^{2} \mathrm{C}=\mathrm{C}$ bonds). $\mathrm{Fe} 2 \mathrm{p}_{3 / 2}$ and Fe $2 p_{1 / 2}$ XPS spectra were fitted based on the contributions from four groups $\left(\mathrm{Fe}^{2+}+\mathrm{N}, \mathrm{Fe}^{3+}+\mathrm{N}, \mathrm{Fe}\right.$ oxide, and Fe satellite).

\section{Electrochemical measurements}

Electrochemical measurements were conducted at room temperature on an Autolab PGSTAT128N (Metrohm, Netherlands) with a rotating-disk electrode (RDE) and a rotating ringdisk electrode (RRDE) system (PINE, Inc.). A GC RDE (diameter: $5 \mathrm{~mm}$; geometric area: $0.196 \mathrm{~cm}^{2}$ ) coated with an electrocatalyst, an $\mathrm{Ag} / \mathrm{AgCl}$ electrode in saturated $\mathrm{KCl}$, and a Pt plate electrode $\left(0.8 \mathrm{~cm}^{2}\right)$ were used as the working, reference, and counter electrodes, respectively. The potential $v s . \mathrm{Ag} / \mathrm{Ag} \mathrm{Cl}$ was converted to the reversible hydrogen electrode (RHE) scale by the following equation:

$$
E_{(v s . \mathrm{RHE})}=E_{(v s . \mathrm{Ag} / \mathrm{AgCl})}+0.197+0.059 \times \mathrm{pH}
$$

The ER(FePc/GO) electrocatalyst was prepared by applying a potential to the FePc/GO (GO $10 \mu \mathrm{g}$, FePc $10 \mu \mathrm{g}$ ) on a GC electrode in $\mathrm{N}_{2}$-saturated $0.1 \mathrm{M} \mathrm{KOH}$, as already mentioned (resulting in an Fe loading of $0.090 \mathrm{~mol}_{\mathrm{Fe}} \mathrm{cm}^{-2}$ ). For the comparison, an ink containing a commercial Pt/C catalyst was prepared by sonicating $5 \mathrm{mg}$ of $20 \mathrm{wt} \% \mathrm{Pt} / \mathrm{C}$ (EC-20, Pt on Vulcan XC-72, ElectroChem, Inc), $40 \mu \mathrm{L}$ of 5 wt $\%$ Nafion suspension (Wako), and $1.66 \mathrm{~mL}$ of ethanol (99.5\%, Wako) for $1 \mathrm{~h}$ and then dropping $5 \mu \mathrm{L}$ of the resultant suspension onto a GC electrode (resulting in a Pt loading of $0.077 \mathrm{~mol}_{\mathrm{Pt}} \mathrm{cm}^{-2}$ ).

The cyclic voltammetry (CV) and RRDE measurements were conducted at a scanning rate of $10 \mathrm{mV} \mathrm{s}^{-1}$ in an $\mathrm{O}_{2}$-saturated $0.1 \mathrm{M} \mathrm{KOH}$ solution, a $0.1 \mathrm{M} \mathrm{KOH}$ solution containing an electrolyte such as $\mathrm{KCl}$ or $\mathrm{KNO}_{3}$. The tolerance test toward methanol was conducted at $0.8 \mathrm{~V}$ (vs. $\mathrm{RHE}$ ) in $\mathrm{O}_{2}$-saturated $0.1 \mathrm{M} \mathrm{KOH}$ at $500 \mathrm{rpm}$ using a chronoamperometric method. A stability test of the as-prepared catalysts for ORR was conducted at $0.5 \mathrm{~V}$ (vs. RHE) in $\mathrm{O}_{2}$-saturated $0.1 \mathrm{M} \mathrm{KOH}$ at $1600 \mathrm{rpm}$ using a chronoamperometric method.

The hydrogen peroxide yields $\left(\mathrm{H}_{2} \mathrm{O}_{2} \%\right)$ and the electron transfer number $(n)$ were calculated from the RRDE data using the equations

$$
\begin{gathered}
\mathrm{H}_{2} \mathrm{O}_{2} \%=\frac{200 \times I_{\mathrm{r}}}{N \times I_{\mathrm{d}}+I_{\mathrm{r}}} \\
n=\frac{4 \times N \times I_{\mathrm{d}}}{N \times I_{\mathrm{d}}+I_{\mathrm{r}}}
\end{gathered}
$$

where $I_{\mathrm{d}}$ is the disk current, $I_{\mathrm{r}}$ is the ring current, and $N=0.25$ is the collection efficiency of the Pt-ring electrode.

\section{Theoretical calculations}

Density functional theory (DFT) calculations were performed using the Cambridge Sequential Total Energy Package (CASTEP) program in the Materials Studio software package. ${ }^{29}$ The generalized gradient approximation of Perdew-Burke-Ernzerhof was used for the exchange-correlation potential; a planewave kinetic energy cutoff of $400 \mathrm{eV}$ was used here. ${ }^{30}$ van der Waals (vdW) forces were corrected using the D2 method of Grimme. ${ }^{31}$ The convergence criterion was set to $0.05 \mathrm{eV} \AA^{-1}$ for the force and $10^{-5} \mathrm{eV}$ per atom for the energy. We applied an exchange energy $(J)$ of $1 \mathrm{eV}$ for Fe 3d orbitals. ${ }^{32}$

In the present study, the structure of an $\mathrm{O}$ atom on a graphene framework and an FePc molecule on top of it was regarded as $\mathrm{ER}(\mathrm{FePc} / \mathrm{GO})$.

\section{Results and discussion}

\section{Structure of GO}

Fig. 1a shows an AFM image of GO sheets exfoliated in DMF. The thickness of the GO sheet was $\sim 1.0 \mathrm{~nm}$, indicating that GO was completely exfoliated to single layers in the DMF. Fig. $1 \mathrm{~b}$ shows the C $1 s$ XPS spectrum of a GO sheet. The spectrum of the
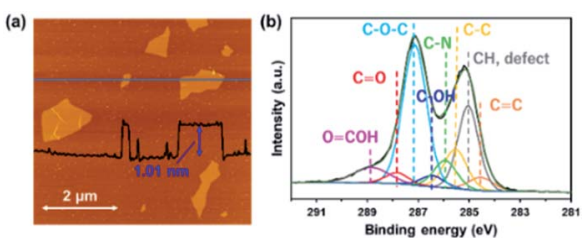

Fig. 1 (a) AFM image and (b) the C 1s XPS spectrum of a GO sheet exfoliated in DMF. 


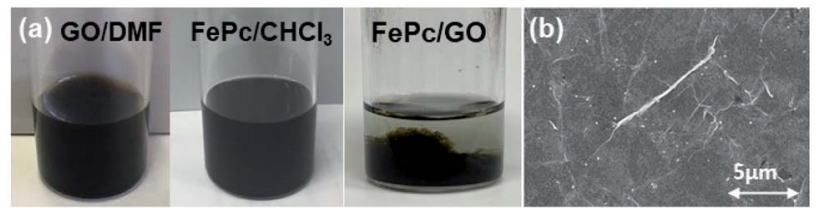

Fig. 2 (a) Photographs of GO/DMF dispersions, an $\mathrm{FePc} / \mathrm{CHCl}_{3}$ dispersion, and a mixture of these two dispersions. (b) SEM image of $\mathrm{ER}(\mathrm{FePc} / \mathrm{GO})$.

GO sheet shows two main peaks at 285.1 and $287.1 \mathrm{eV}$; the former is derived from the graphene domain, and the latter arises from O-containing functional groups. The degree of oxidation $(\mathrm{O} /(\mathrm{C}+\mathrm{O}))$ was 0.36 , which indicates that $\mathrm{GO}$ was sufficiently oxidized. Peaks in the $\mathrm{C} 1 \mathrm{~s}$ spectra were assigned to various $\mathrm{O}$-containing functional groups (i.e., $\mathrm{C}=\mathrm{O}, \mathrm{C}-\mathrm{O}-\mathrm{C}$, and $\mathrm{COOH})$ and a $\mathrm{C}=\mathrm{C}$ group. The $\mathrm{GO}$ sheets were negatively charged in the DMF solution because of their $\mathrm{O}$ functional groups, which enabled the formation of a nanohybrid between the GO sheets and the FePc via electrostatic interactions and $\pi$ $\pi$ interactions between the FePc and the $\mathrm{O}$ atoms in the GO. ${ }^{22}$

\section{Structure of FePc/GO and ER(FePc/GO)}

Fig. 2a shows photographs of a GO-dispersed DMF solution (GO/DMF), an $\mathrm{CHCl}_{3}$ solution with dissolved FePc (FePc/ $\mathrm{CHCl}_{3}$ ), and a mixture of these two dispersions. The single layer GO was well dispersed in DMF without aggregating, and the $\mathrm{FePc} / \mathrm{CHCl}_{3}$ exhibited high dispersion stability, remaining dispersed even after 1 month. In a previous study, methanol and/or DMF were used to dissolve FePc. ${ }^{22,23}$ The state of dispersion of FePc in methanol and DMF was unstable, therefore, FePc dispersed EtOH and/or DMF was precipitated at the bottom after 1 day (see Fig. S1, ESI†). Because of strong interaction between the $\mathrm{GO}$ and $\mathrm{FePc}$, the $\mathrm{FePc} / \mathrm{GO}$ nanocomposite was immediately produced when the $\mathrm{GO} / \mathrm{DMF}$ and $\mathrm{FePc} / \mathrm{CHCl}_{3}$ solutions were mixed. The FePc/GO nanocomposite was directly prepared on the GC electrodes. The FePc/GO composite was electrochemically reduced at $-0.8 \mathrm{~V} v s$. $\mathrm{Ag} / \mathrm{AgCl}$ in a $\mathrm{KOH}$ aqueous solution. The electrochemically reduced $\mathrm{FePc} / \mathrm{GO}$ composite was denoted as $\mathrm{ER}(\mathrm{FePc} / \mathrm{GO})$. Fig. $2 \mathrm{~b}$ shows an FE-SEM image of the ER(FePc/GO) on the electrode. Only GO-derived wrinkle structure was observed in the SEM image, indicating that the FePc molecules were adsorbed uniformly on the rGO surface.
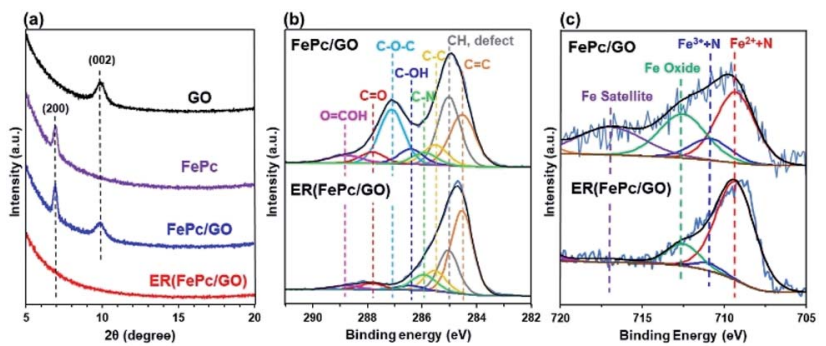

Fig. 3 (a) XRD patterns of GO, FePc, GC-plate FePc/GO, and ER(FePc/ $\mathrm{GO}) ;\left(\right.$ (b) $\mathrm{C} 1 \mathrm{~s}$ and (c) Fe $2 \mathrm{p}_{3 / 2}$ XPS spectra of FePc/GO and ER(FePc/GO) on a GC plate.
The XRD patterns of the GO, FePc, FePc/GO, and ER(FePc/ GO) on a GC plate are shown in Fig. 3a. The strongest XRD peaks of GO and FePc appeared at $\sim 9.9^{\circ}$ and $\sim 7.0^{\circ}$, corresponding to the (002) planes of GO and the (200) planes of FePc, respectively. The XRD pattern of FePc/GO shows peaks attributable to both GO and FePc, indicating that restacked GO and recrystallized FePc were present in the FePc/GO. After electrochemical reduction, the peaks attributed to GO and FePc disappeared. Their disappearance is attributed to the desorption of residual restacked GO and recrystallized FePc; a composite with a dense structure at the nanolevel was produced.

XPS measurements were performed to investigate the chemical states of the GO and $\mathrm{Fe}$ in the $\mathrm{FePc} / \mathrm{GO}$ and $\mathrm{ER}(\mathrm{FePc} /$ GO) nanocomposites. Fig. $3 \mathrm{~b}$ shows the $\mathrm{C} 1 s$ spectra of FePc/GO and $\mathrm{ER}(\mathrm{FePc} / \mathrm{GO})$. The intensities of the peaks of the epoxy groups $(287.1 \mathrm{eV})$ in $\mathrm{FePc} / \mathrm{GO}$ greatly decreased after the electrochemical reduction process, indicating that GO was successfully reduced. The reduction of GO enables the electrocatalyst to attain the high electrical conductivity required for high catalytic activity. Fig. $3 \mathrm{c}$ shows the $\mathrm{Fe} 2 \mathrm{p}_{3 / 2}$ spectra of $\mathrm{FePc} /$ $\mathrm{GO}$ and $\mathrm{ER}(\mathrm{FePc} / \mathrm{GO})$. A comparison of these spectra reveals that the $\mathrm{Fe}^{3+}$ and $\mathrm{Fe}^{2+}$ peaks of $\mathrm{ER}(\mathrm{FePc} / \mathrm{GO})$ are less intense and more intense, respectively, than those of $\mathrm{FePc} / \mathrm{GO}$. This result indicates that the $\mathrm{Fe}^{3+}$ was reduced to $\mathrm{Fe}^{2+}$ under the applied potential. $\mathrm{Fe}^{2+}$ generally exhibits greater activity than $\mathrm{Fe}^{3+}$ toward the ORR. ${ }^{22}$ We therefore expected the ER(FePc/GO), which exhibits high electrical conductivity and contains $\mathrm{Fe}^{2+}$, to demonstrate high ORR activity.

\section{Catalytic activities of FePc/GO and ER(FePc/GO)}

To investigate the ORR activity of FePc/GO and ER(FePc/GO), CV measurements were performed in $0.1 \mathrm{M} \mathrm{KOH}$ solution with $\mathrm{N}_{2}$ or $\mathrm{O}_{2}$ aeration. Fig. $4 \mathrm{a}$ and $\mathrm{b}$ shows the current-voltage $(I-V)$ curves for the $\mathrm{FePc} / \mathrm{GO}$ and $\mathrm{ER}(\mathrm{FePc} / \mathrm{GO})$ nanocomposites. The
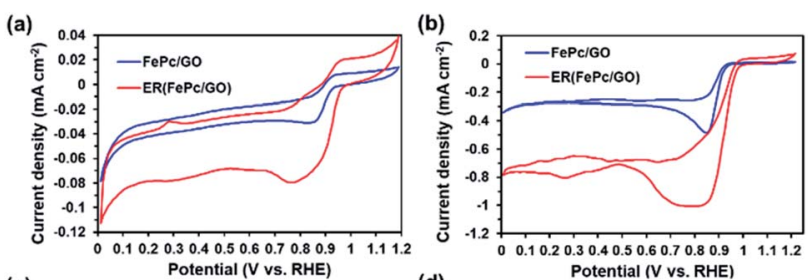

(c)
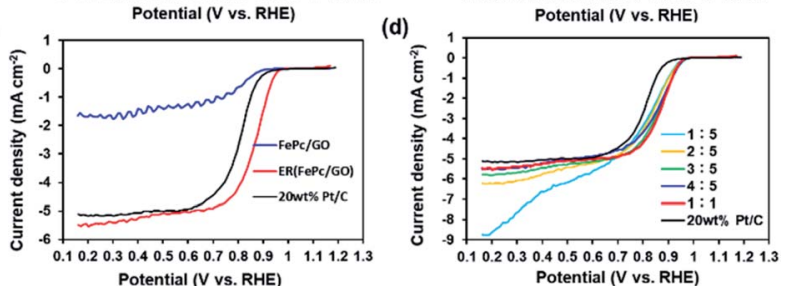

Fig. 4 Cyclic voltammograms of FePc/GO and ER(FePc/GO) in (a) $\mathrm{N}_{2}$ and (b) $\mathrm{O}_{2}$-saturated $0.1 \mathrm{M} \mathrm{KOH}$ solutions. (c) ORR polarization curves of $\mathrm{FePc} / \mathrm{GO}, \mathrm{ER}(\mathrm{FePc} / \mathrm{GO})$, and $20 \mathrm{wt} \% \mathrm{PtC}$ in $\mathrm{O}_{2}$-saturated $0.1 \mathrm{M} \mathrm{KOH}$, as a recorded at an electrode rotation rate of $1600 \mathrm{rpm}$ and a scan rate of $10 \mathrm{mV} \mathrm{s}^{-1}$. (d) RDE measurements of $\mathrm{ER}(\mathrm{FePc} / \mathrm{GO}$ ) mixed with FePc and $\mathrm{GO}$ in various ratios, as recorded using $\mathrm{O}_{2}$-saturated $0.1 \mathrm{M} \mathrm{KOH}$, an electrode rotation rate of $1600 \mathrm{rpm}$, and a scan rate of $10 \mathrm{mV} \mathrm{s}^{-1}$. 


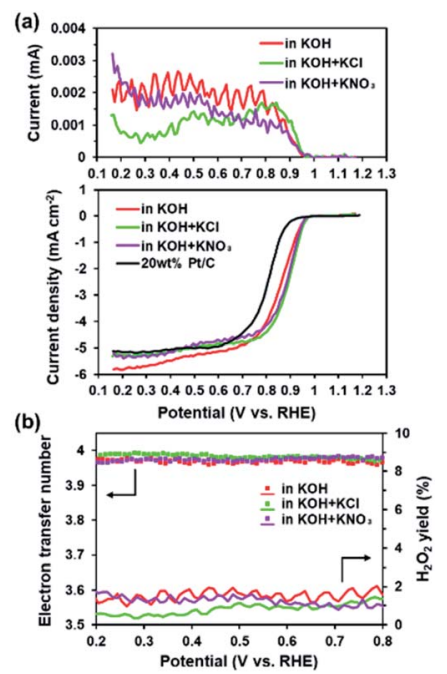

Fig. 5 (a) RRDE measurements of the $E R(F e P c / G O)$ nanocomposite in $\mathrm{O}_{2}$-saturated $0.1 \mathrm{M} \mathrm{KOH}$ and $0.1 \mathrm{M} \mathrm{KOH}$ containing various electrolytes; the measurements were conducted with a rotation rate of $1600 \mathrm{rpm}$ and at a scan rate $10 \mathrm{mV} \mathrm{s}^{-1}$. (b) Electron transfer numbers and percentage $\mathrm{H}_{2} \mathrm{O}_{2}$ yield of $\mathrm{ER}\left(\mathrm{FePc} / \mathrm{GO}\right.$ ) in $\mathrm{O}_{2}$-saturated $0.1 \mathrm{M} \mathrm{KOH}$ and $0.1 \mathrm{M} \mathrm{KOH}$ containing various electrolytes.

cyclic voltammograms of the $\mathrm{FePc} / \mathrm{GO}$ and $\mathrm{ER}(\mathrm{FePc} / \mathrm{GO})$ nanocomposites in the $\mathrm{N}_{2}$-saturated $0.1 \mathrm{M} \mathrm{KOH}$ solution (Fig. 4a) show only redox peaks of $\mathrm{Fe}^{3+}$ and $\mathrm{Fe}^{2+}$. However, the cyclic voltammograms of the same materials in the $\mathrm{O}_{2}$-saturated $0.1 \mathrm{M}$ $\mathrm{KOH}$ solution (Fig. 4b) show negative currents, which we attributed to the ORR. The onset potentials ( $\left.E_{\text {onset }}\right)$ of the FePc/ $\mathrm{GO}$ and $\mathrm{ER}(\mathrm{FePc} / \mathrm{GO})$ were $0.92 \mathrm{~V}$ and $0.98 \mathrm{~V}$ ( $v s$. RHE), respectively. The $\mathrm{ER}(\mathrm{FePc} / \mathrm{GO})$ showed a higher $E_{\text {onset }}$ than the FePc/ GO because of its higher electrical conductivity and greater $\mathrm{Fe}^{2+} / \mathrm{Fe}^{3+}$ ratio. The high ORR activity of the $\mathrm{ER}(\mathrm{FePc} / \mathrm{GO})$ composite was confirmed via RDE experiments. The ORR polarization curves in Fig. $4 \mathrm{c}$ reveal that the ORR onset and halfwave potential of $\mathrm{ER}(\mathrm{FePc} / \mathrm{GO})$ are 0.97 and $0.86 \mathrm{~V}$, which are greater those of the commercial $20 \mathrm{wt} \% \mathrm{Pt} / \mathrm{C}\left(E_{\text {onset }}=0.91 \mathrm{~V}, E_{1 / 2}\right.$ $=0.81 \mathrm{~V})$. The ER(FePc/GO) nanocomposite containing FePc and GO in a $1: 1$ ratio exhibited the highest ORR activity, as shown in Fig. 4d.

\section{Effect of adding electrolyte on the ORR activity}

The presence of electron-withdrawing ions near FePc leads to high ORR activity because of a decrease in the electron density of Fe atoms. ${ }^{33,34}$ Therefore, ORR measurements of the ER(FePc/ GO) composite were performed after an electrolyte such as $\mathrm{KCl}$ or $\mathrm{KNO}_{3}$ was added to the $0.1 \mathrm{M} \mathrm{KOH}$ solution. The ORR polarization curves in Fig. 5 a show that the ORR onset and halfwave potential positively shifted upon addition of $\mathrm{KCl}$ or $\mathrm{KNO}_{3}$. These results clearly indicate that the ORR activity was improved by the addition of $\mathrm{KCl}$ or $\mathrm{KNO}_{3}$ to the electrolyte. The average electron transfer number of $\mathrm{ER}(\mathrm{FePc} / \mathrm{GO})$ in $0.1 \mathrm{M} \mathrm{KOH}$ solutions with $\mathrm{KCl}$ and $\mathrm{KNO}_{3}$ was 3.97 and 3.98, respectively. This result indicates that the reduction of $\mathrm{O}_{2}$ to $\mathrm{OH}^{-}$over $\mathrm{ER}(\mathrm{FePc} / \mathrm{GO})$ occurred via a four-electron transfer process. The

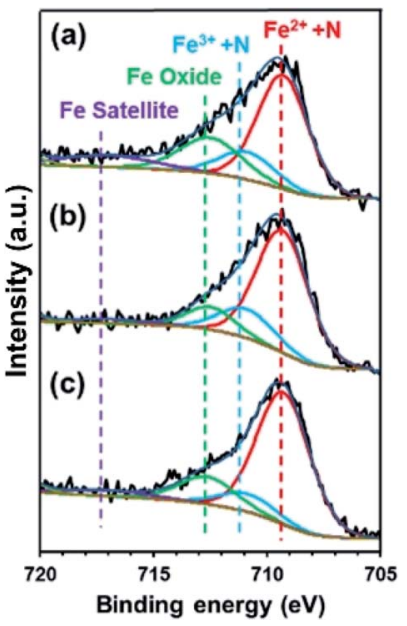

Fig. $6 \mathrm{Fe} 2 \mathrm{p}_{3 / 2}$ spectra of $\mathrm{ER}(\mathrm{FePc} / \mathrm{GO})$ subjected to an applied potential (0.57 V vs. RHE, $10 \mathrm{~min}$ ) in (a) $0.1 \mathrm{M} \mathrm{KOH}$ solution, (b) $0.1 \mathrm{M}$ $\mathrm{KOH}$ solution containing $0.1 \mathrm{M} \mathrm{KCl}$, and (c) $0.1 \mathrm{M} \mathrm{KOH}$ solution containing $0.1 \mathrm{M} \mathrm{KNO}_{3}$.

$\mathrm{H}_{2} \mathrm{O}_{2}$ yield was smaller than $2 \%$ in the potential range from 0.2 to $0.8 \mathrm{~V}$ at all of the samples, as shown in Fig. $5 \mathrm{~b}$, which indicates low peroxide formation during the ORR.

To confirm the effect of $\mathrm{Cl}^{-}$and $\mathrm{NO}_{3}{ }^{-}$anions on the electron density of the Fe in FePc, XPS measurements were performed on the $\mathrm{ER}(\mathrm{FePc} / \mathrm{GO})$ nanocomposite after a potential was applied in each solution saturated with $\mathrm{O}_{2}$; the results are shown in Fig. 6 . The $\mathrm{Fe}^{2+} / \mathrm{Fe}^{3+}$ ratio of $\mathrm{ER}(\mathrm{FePc} / \mathrm{GO})$ subjected to an applied potential $(0.57 \mathrm{~V} v s$. RHE, $10 \mathrm{~min})$ in $0.1 \mathrm{M} \mathrm{KOH}$ solution, $0.1 \mathrm{M}$ $\mathrm{KOH}$ solution containing $0.1 \mathrm{M} \mathrm{KCl}$, and $0.1 \mathrm{M} \mathrm{KOH}$ solution containing $0.1 \mathrm{M} \mathrm{KNO}_{3}$ is $3.7,4.0$, and 7.0, respectively. These results show that the presence of an electrolyte in the $\mathrm{KOH}$ solution inhibits the oxidation of $\mathrm{Fe}^{2+}$, enabling it to remain in the more highly active divalent state.

When 3.0 M methanol was added to the $0.1 \mathrm{M} \mathrm{KOH}$ electrolyte solution, $\mathrm{ER}(\mathrm{FePc} / \mathrm{GO})$ showed a stable amperometric response without a substantial loss in current density (Fig. 7a), indicating a superior tolerance to methanol addition. In contrast, the commercial $20 \mathrm{wt} \% \mathrm{Pt} / \mathrm{C}$ showed a $60 \%$ decrease in current after methanol addition. This result suggests that $\mathrm{ER}(\mathrm{FePc} / \mathrm{GO})$ could also be used as a methanol-tolerant cathode catalyst in direct methanol fuel cells.
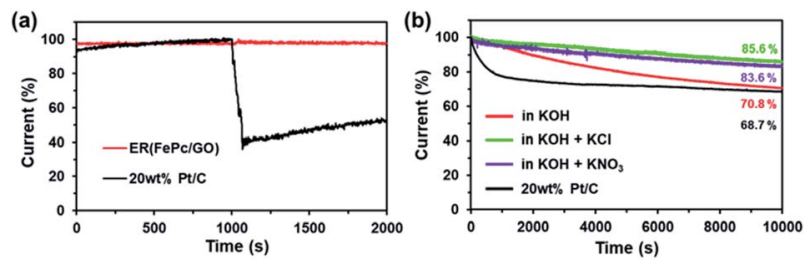

Fig. 7 (a) Tests of the methanol tolerance of $E R(F e P c / G O)$ in $0.1 \mathrm{M}$ $\mathrm{KOH}$ and in $0.1 \mathrm{M} \mathrm{KOH}$ with various electrolytes at $0.5 \mathrm{~V}$ (vs. RHE) and $500 \mathrm{rpm}$. (b) Current-time ( $i-t)$ curves of $\mathrm{ER}(\mathrm{FePc} / \mathrm{GO}$ ) at $0.5 \mathrm{~V}$ (vs. $\mathrm{RHE}$ ) in $\mathrm{O}_{2}$-saturated $0.1 \mathrm{M} \mathrm{KOH}$ and $0.1 \mathrm{M} \mathrm{KOH}$ with various electrolytes at $1600 \mathrm{rpm}$. 


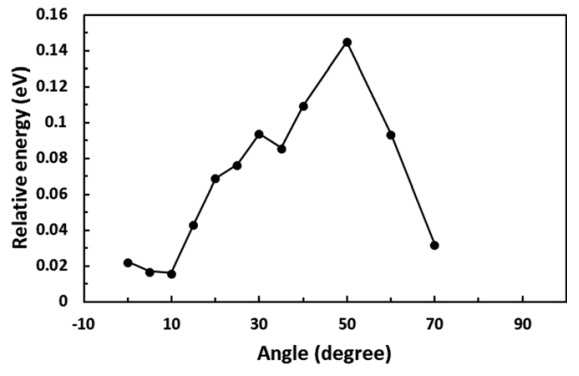

Fig. 8 Optimization of the installation angle of FePc to graphene.

In addition to activity, durability is a major factor affecting the suitability of electrocatalysts for use in fuel cells. As shown in Fig. $7 \mathrm{~b}$, the current of $\mathrm{ER}(\mathrm{FePc} / \mathrm{GO})$ at $0.5 \mathrm{~V}$ (vs. RHE) decreased to $70.8 \%$ after $10000 \mathrm{~s}$ in $0.1 \mathrm{M} \mathrm{KOH}$ at a rotation rate of $1600 \mathrm{rpm}$, which represents greater durability than that of the $20 \mathrm{wt} \% \mathrm{Pt} / \mathrm{C}$. When an electrolyte was added to the KOH solution, the durability was strongly affected: the ER(FePc/GO) maintained better than $80 \%$ of its initial current. This result is attributed to the oxidation of Fe in FePc being suppressed by the electrolyte.

\section{Theoretical calculations}

First, we optimized the structure of ER(FePc/GO) using DFT calculations. A graphene framework with a $\mathrm{C}-\mathrm{O}-\mathrm{C}$ oxygen functional group placed on it was considered as reduced $\mathrm{GO}$, and an FePc molecule was placed on the $\mathrm{O}$ atom. Structural optimization showed that the distance between $\mathrm{Fe}$ and $\mathrm{O}$ was $1.962 \AA$ (see Fig. S4, ESI $\dagger$ ). The angle of FePc to the graphene framework was also optimized as shown in Fig. 8 and 9. The total enthalpy was depended on the angle of FePc to the
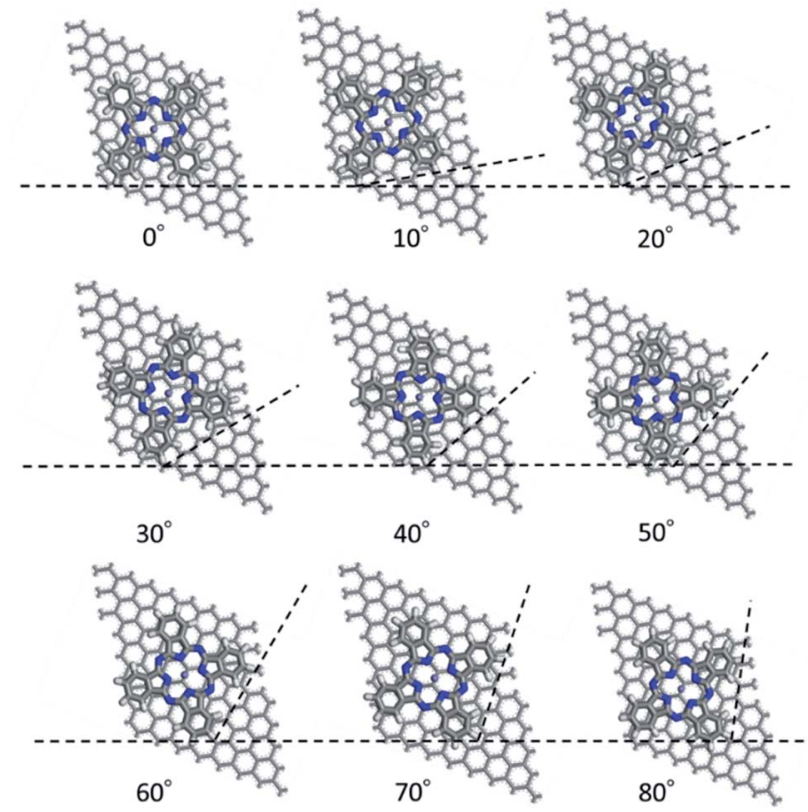

Fig. 9 Structure of $E R(F e P c / G O)$ depending on the installation angle of FePc to the graphene framework.

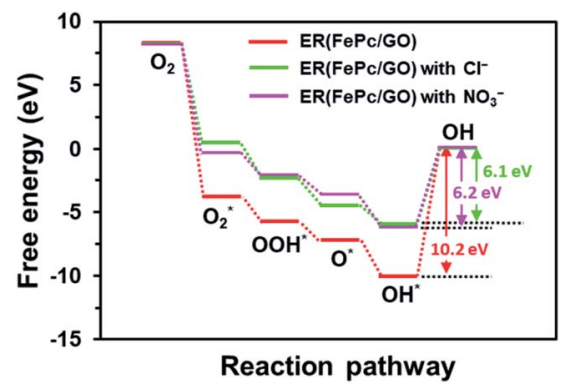

Fig. 10 Free energy diagram of ORR for ER(FePc/GO).

graphene framework, and the structure $10^{\circ}$ was the most stable structure among the nine structure shown in Fig. 9, where the lamination deviations were observed between the four 6-membered carbon rings of the FePc and the 6membered carbon rings of the GO surface. Next, the DFT calculations to analyze the ORR mechanism of ER(FePc/GO) under alkaline conditions with and without electronwithdrawing groups such as $\mathrm{Cl}^{-}$were performed. The $4 \mathrm{e}^{-}$ pathway of the ORR in the alkaline medium is expressed as follows: ${ }^{35}$

Overall reaction: $\mathrm{O}_{2}+2 \mathrm{H}_{2} \mathrm{O}+4 \mathrm{e}^{-} \rightarrow 4 \mathrm{OH}^{-}$

$$
\begin{gathered}
*+\mathrm{O}_{2}+2 \mathrm{H}_{2} \mathrm{O}+4 \mathrm{e}^{-} \rightarrow * \mathrm{O}_{2}+2 \mathrm{H}_{2} \mathrm{O}+4 \mathrm{e}^{-} \\
* \mathrm{O}_{2}+2 \mathrm{H}_{2} \mathrm{O}+4 \mathrm{e}^{-} \rightarrow * \mathrm{OOH}+(\mathrm{OH})^{-}+\mathrm{H}_{2} \mathrm{O}+3 \mathrm{e}^{-} \\
* \mathrm{OOH}+(\mathrm{OH})^{-}+\mathrm{H}_{2} \mathrm{O}+3 \mathrm{e}^{-} \rightarrow * \mathrm{O}+2(\mathrm{OH})^{-} \\
+\mathrm{H}_{2} \mathrm{O}+2 \mathrm{e}^{-} \\
* \mathrm{O}+2(\mathrm{OH})^{-}+\mathrm{H}_{2} \mathrm{O}+2 \mathrm{e}^{-} \rightarrow * \mathrm{OH}+3(\mathrm{OH})^{-}+\mathrm{e}^{-} \\
* \mathrm{OH}+3(\mathrm{OH})^{-}+\mathrm{e}^{-} \rightarrow *+4(\mathrm{OH})^{-}
\end{gathered}
$$

Here, * denotes the active site of FePc.

The free-energy diagrams of $\mathrm{ER}(\mathrm{FePc} / \mathrm{GO})$ in an alkaline medium with and without $\mathrm{Cl}^{-}$from the reaction (1) to (5) are shown in Fig. 10. Fig. 11 shows the structures corresponded to the each step in the energy diagrams in Fig. 10. In both the presence and absence of $\mathrm{Cl}^{-}$, the reaction proceeds smoothly from reaction (1) to intermediate reaction (4); however, the

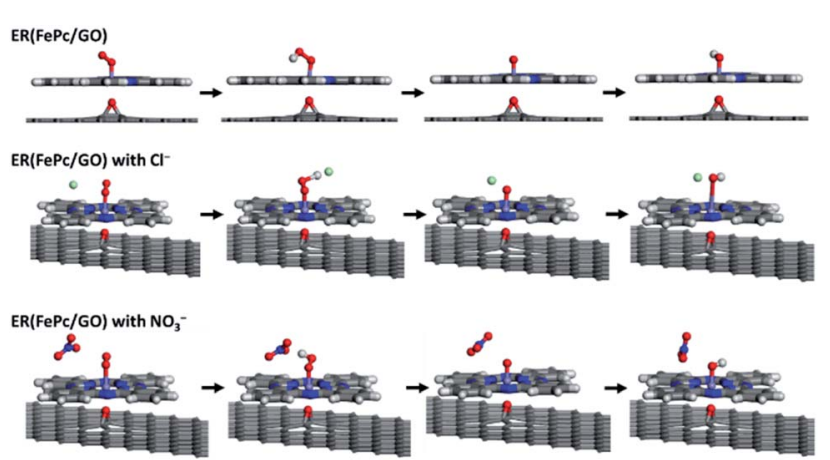

Fig. 11 Optimized structure of $\mathrm{ER}(\mathrm{FePc} / \mathrm{GO})$ along the ORR reaction pathway. 
energy barrier of intermediate reaction (5), in which the $\mathrm{OH}$ adsorbed onto the electrocatalyst is desorbed, is large. Additionally, each intermediate is destabilized more in the presence of $\mathrm{Cl}^{-}$than in its absence. This destabilization causes the energy barrier of $10.2 \mathrm{eV}$ for the intermediate reaction (5) in the absence of $\mathrm{Cl}^{-}$to decrease to $6.1 \mathrm{eV}$, which means that the presence of $\mathrm{Cl}^{-}$promotes the ORR.

\section{Conclusions}

The FePc/rGO nanocomposite without agglomeration has been developed by electrochemically reducing a mixture of completely monolayer GO dispersion and well-dispersed FePc in $\mathrm{CHCl}_{3}$. The $\mathrm{FePc} / \mathrm{rGO}$ nanocomposite exhibited high ORR activity, with an ORR onset and half-wave potential of 0.97 and $0.86 \mathrm{~V}$, respectively, which are greater than those of a commercially available $20 \mathrm{wt} \% \mathrm{Pt} / \mathrm{C}$ catalyst. The high ORR activity is attributed to that the FePc/GO nanocomposite has not only nanolevel structure but also higher electrical conductivity and greater $\mathrm{Fe}^{2+} / \mathrm{Fe}^{3+}$ ratio. The ORR activity could be further improved by adding an electrolyte such as $\mathrm{KCl}$ or $\mathrm{KNO}_{3}$. The theoretical calculations indicated that the presence of $\mathrm{Cl}^{-}$and $\mathrm{NO}_{3}{ }^{-}$ions lowered the conversion energy barrier, supporting the experimental results.

\section{Conflicts of interest}

There are no conflicts to declare.

\section{Acknowledgements}

This work was supported by JSPS KAKENHI Grant Numbers JP18H01835 and 19K05673.

\section{Notes and references}

1 I. Jung, D. A. Dikin, R. D. Piner and R. S. Ruoff, Nano Lett., 2008, 8, 4283.

2 K. Hatakeyama, H. Tateishi, T. Taniguchi, M. Koinuma, T. Kida, S. Hayami, H. Yokoi and Y. Matsumoto, Chem. Mater., 2014, 26, 5598.

3 T.-F. Yeh, J.-M. Syu, C. Cheng, T.-H. Chang and H. Teng, Adv. Funct. Mater., 2010, 20, 2255.

4 W.-H. Chiang, T.-C. Lin, Y.-S. Li, Y.-J. Yang and Z. Pei, RSC Adv., 2016, 6, 2270.

5 O. C. Compton, B. Jain, D. A. Dikin, A. Abouimrane, K. Amine and S. T. Nguyen, ACS Nano, 2011, 5, 4380.

6 X.-M. Huang, L.-Z. Liu, S. Zhou and J.-J. Zhao, Front. Physiol., 2020, 15, 33301.

7 X. Chen, P. Qian, T. Zhang, Z. Xu, C. Fang, X. Xu, W. Chen, P. Wu, Y. Shen, S. Li, J. Wu, B. Zheng, W. Zhang and F. Huo, Chem. Commun., 2018, 54, 3936.

8 M. Jahan, Z. Liu and K. P. Loh, Adv. Funct. Mater., 2013, 23, 5363.
9 S. Liu, H. Zhang, Q. Zhao, X. Zhang, R. Liu, X. Ge, G. Wang, H. Zhao and W. Cai, Carbon, 2016, 106, 74.

10 L. Jiao, Y.-X. Zhou and H.-L. jiang, Chem. Sci., 2016, 7, 1690. 11 A. Dutta and J. Ouyang, Appl. Catal., B, 2014, 158, 119.

12 Y. Lin, Y.-Y. Wu, G.-J. Lv, T. Pu, X.-Q. He and L.-L. Cui, Electrochim. Acta, 2013, 112, 269.

13 X. Zheng, Y. Cao, D. Liu, M. Cai, J. Ding, X. Liu, J. Wang, W. Hu and C. Zhong, ACS Appl. Mater. Interfaces, 2019, 11, 15662.

14 Z. Lin, G. H. Waller, Y. Lin, M. Liu and C.-P. Wong, Nano energy, 2013, 2, 241.

15 D. Liu, L. Tao, D. Yan, Y. Zou and S. Wang, ChemElectroChem, 2018, 5, 1775.

16 Y.-J. Wang, D. P. Wilkinson and J. Zhang, Chem. Rev., 2011, 111, 7625.

17 A. Rabis, P. Rodriguez and T. J. Schmidit, ACS Catal., 2012, 2, 864.

18 G. Wu, A. Santandreu, W. Kellogg, S. Gupta, O. Ogoke, H. Zhang, H.-L. Wang and L. Dai, Nano Energy, 2016, 29, 83. 19 Z. Hu, Z. Guo, Z. Zhang, M. Dou and F. Wang, ACS Appl. Mater. Interfaces, 2018, 10, 12651.

20 J. S. Park and D. W. Chang, Energies, 2020, 13, 4073.

21 W. Wan, C. A. triana, J. Lan, J. Li, C. S. Allen, Y. Zhao, M. Iannuzzi and G. R. Partzke, ACS Nano, 2020, 14, 13279.

22 T. Taniguchi, H. Tateishi, S. Miyamoto, K. Hatakeyama, C. Ogata, A. Funatsu, S. Hayami, Y. Makinose, N. Matsushita, M. Koinuma and Y. Matsumoto, Part. Part. Syst. Charact., 2013, 30, 1063.

23 D. Liu and Y.-T. Long, ACS Appl. Mater. Interfaces, 2015, 7, 24063.

24 J. Guo, X. Yan, Q. Liu, Q. Li, X. Xu, L. Kang, Z. Cao, G. Chai, J. Chen, Y. Wang and J. Yao, Nano Energy, 2018, 46, 347.

25 C.-X. Zhao, B.-Q. Li, J.-N. Liu and Q. Zhang, Angew. Chem., Int. Ed., 2020, 59, 2.

26 T. Sun, L. Xu, D. Wang and Y. Li, Nano Res., 2019, 12, 2067.

27 W. S. Hummers and R. E. Offeman, J. Am. Chem. Soc., 1958, 80, 1339.

28 C. Ogata, R. Kurogi, K. Awaya, K. Hatakeyama, T. Taniguchi, M. Koinuma and Y. Matsumoto, ACS Appl. Mater. Interfaces, 2017, 9, 26151.

29 S. J. Clark, M. D. Segall, C. J. Pickard, P. J. Hasnip, M. I. J. Probert, K. Refson and M. C. Payne, Z. Kristallogr., 2005, 220, 567.

30 J. P. Perdew, K. Burke and M. Ernzerhof, Phys. Rev. Lett., 1996, 77, 3865.

31 S. Grimme, J. Comput. Chem., 2006, 27, 1787.

32 J. Zhou and Q. Sun, J. Am. Chem. Soc., 2011, 133, 15113.

33 J. H. Zagal and M. T. M. Koper, Angew. Chem., Int. Ed., 2016, 55, 14510.

34 A. Pizarro, G. Abarca, C. Gutiérrez-Cerón, D. CortésArriagada, F. Bernardi, C. Berrios, J. F. Silva, M. C. Rezende, J. H. Zagal, R. Oñate and I. Ponce, ACS Catal., 2018, 8, 8406.

35 B. Mukherjee, J. Electrochem. Soc., 2018, 165, 3231. 